\title{
El lector militante
}

\author{
Adriana Petra \\ Universidad Nacional de San Martín / CONICET
}

En el verano de 2019, instalada en la escena de los veranos familiares marplatenses, recibí un correo electrónico de Carlos Altamirano con el asunto "Cultura comunista". Desvié rápidamente el impulso hacia la playa y lo abrí, curiosa. Me enviaba una foto y me contaba que hacía poco él mismo la había recibido de un viejo amigo chaqueño. La imagen mostraba en primer plano a un hombre de pie, de riguroso traje, bigote y gomina. Las manos en la espalda esperando hablarle a un micrófono de cabeza redonda. Más atrás, tres jóvenes mujeres con cintas de luto en sus brazos custodiaban varias coronas de flores. De fondo, un enorme friso retrataba a Stalin flanqueado por las banderas de la Unión Soviética y la Argentina con la leyenda "Gloria eterna al inmortal Stalin". La toma era de 1953 y se trataba del homenaje que el pequeño Partido Comunista de Resistencia le hacía al "padre de los pueblos", muerto en marzo de ese año para conmoción de todo el mundo. Se trataba de una imagen a la vez curiosa y común en la iconografía del comunismo, pero que remitía a una historia familiar. El hombre de traje, el tío Pedro, había sido un comunista fiel, pero su sobrino, el amigo de Carlos, no lo recordaba por eso, sino porque en las calurosas siestas chaqueñas aquel tío, padre de las chicas que lo acompañaban en el ritual, le había "iluminado el mundo de la lectura". ${ }^{1}$

La historia del comunismo desde el punto de vista de los libros y la lectura es paradójica. Para casi todos, una cultura tan rígida y ríspida, tan dada al control y a la sospecha, no podría tener sino una relación tensionada e instrumental con los libros. Un repaso por los incontables manuales soviéticos y las ediciones de los clásicos del marxismo-leninismo-estalinismo,

\footnotetext{
${ }^{1}$ Agradezco a Ana Clarisa Agüero y a Diego García por la conversación sobre este texto y por su siempre aguda y generosa mirada sobre los temas que nos unen desde hace años.
}

aún hoy disponibles por decenas en las librerías de viejo, bastaría para comprobar un catálogo deslucido y acotado a la esfera de la formación militante, aunque de tiradas gigantescas, muchas mayores a los contornos del Partido Comunista Argentino (PCA). Esto es en parte cierto, pero solo en parte.

Los comunistas, como toda la familia de izquierdas, crecieron en una misma edad mediológica, para decirlo con Régis Debray: un ecosistema regido por la razón, el libro, la prensa y el partido político. ${ }^{2}$ Los comunistas, como el resto de las izquierdas, concebían los impresos en el marco de la tradición ilustrada de la que formaban parte, pero en la historia de sus experiencias realmente existentes, empezando por la Unión Soviética, los libros cumplieron más de una función. No es exagerado decir que no hubo en la historia contemporánea un Estado que haya editado más cantidad de libros y dado a la cultura -o, más precisamente, a la "alta" culturaun estatus público tan elevado. No deja de ser curioso: en los peores años del terror estalinista, la intelligentsia se convirtió en una elite privilegiada, y por eso mismo celosamente custodiada. En el fatídico año de 1937, la celebración del centenario de Pushkin se convirtió en una fiesta nacional soviética y se editaron, en menos de un año, veinte millones de ejemplares de sus obras. Algunos de ellos circularon por los cinco continentes, traducidos a más de una veintena de idiomas gracias al sistema de traducción, impresión y circulación que hasta su ocaso promovieron la Internacional Comunista y el gobierno soviético. Es en la escala y la organización donde radica la particular veta comunista de la grafosfera: el comunismo soviético, además de un régimen de poder estatal, una ideología y un movimiento político internacional, fue una fabulosa máquina

${ }^{2}$ Régis Debray, "El socialismo y la imprenta. Un ciclo vital", en New Left Review, n 46, 2007, pp. 5-26. 
de producción y circulación de impresos y un caso único de mundialización de una cultura militante. Por eso me gustaría referirme al comunismo como un "mundo", esto es, un espacio transnacional e interconectado dentro del cual hombres y mujeres organizaron un sentido de pertenencia y de relaciones estructurado por una ideología y una sensibilidad, pero también por el movimiento de agentes y artefactos político-culturales que tramaron un ritmo común de experiencias, percepciones y posiciones. En el más recóndito pueblo, ser comunista era pertenecer a ese vasto mundo.

Entonces, ¿existe un "lector comunista"? Y si existe ¿cómo se llega a serlo? ¿Qué significa leer como un comunista? Ignoro si hay respuestas para estos interrogantes e incluso si son los correctos. La lectura y su historia es un terreno siempre más inestable y farragoso que el estudio de los libros, la edición e incluso la escritura, y el vínculo entre lectura y culturas políticas es aún una terra incognita. Pero para este caso en particular, el caso de Carlos Altamirano "lector comunista", creo que pueden plantearse dos cuestiones importantes, bajo la forma de una relación: la que se establece entre lectura, militancia y política, por un lado, y entre lectura y comunidad, por el otro. En este texto intentaré seguir las estaciones de una vida lectora a través de los hilos de esta doble relación.

Una estación es un período de tiempo, de un año o de una vida, que se caracteriza por algo: por determinadas condiciones ambientales, por la longitud de los días o por un tiempo destinado a una tarea. Cuando esas condiciones cambian, una nueva estación se abre. En estas memorias de lector, el pasaje de una estación a otra se organiza mediante los cruces entre la experiencia vital, la política y las vicisitudes de la vida nacional. Así es que la primera, acunada por el tiempo y el paisaje de la infancia, arranca en el verano de 1946, cuando el primer libro llega por vía materna en el mismo momento en el que Juan Domingo Perón asume la presidencia, y termina casi diez años después, cuando el golpe de 1955 abre una instancia de efervescencia cultural y política que desborda los habituales límites porteños y llega hasta Corrientes. Allí hay ahora un estudiante de secundaria que ha encontrado su sociabilidad en la filas de la Acción Católica y que enterado de la polémica sobre la Ley Domingorena se pone del lado de los libres, precisamente cuando a la ciudad provinciana llegan, bajo la forma de visitas culturales, las voces de ese filón poderoso de la cultura argentina que se identificaba con el espacio liberal-democrático y la identidad antifascista y por ello antiperonista, al que también pertenecían los comunistas. En ese clima aparece por primera vez el nombre de Arturo Frondizi, que al poco tiempo será motivo de una temporada en la cárcel y tres décadas después de una biografía que pone en su centro las siempre tensas relaciones entre la política y la vida intelectual. ${ }^{3}$ También en ese momento, como parte del movimiento que pronto lo llevará a abandonar el compromiso católico y a transformarse en un "estudiante reformista", resuena el nombre de Carlos Marx junto al de José Ingenieros, un clásico de la tradición letrada de las izquierdas argentinas.

En la vida estudiantil de provincia, el ingreso a la universidad suele coincidir con el descubrimiento de la política y a menudo con un cambio de paisaje, el que viene con la opción o la necesidad de irse a "estudiar afuera". La llegada de Carlos a la Universidad Nacional del Litoral para estudiar medicina es producto tanto de un apego al mandato familiar como de un distanciamiento de ese núcleo, cuya "buena voluntad cultural" venía siendo decisiva: la madre, el padre y el hermano, cada uno a su modo, formaron un lector y lo dotaron de una serie de disposiciones y valoraciones sobre los objetos impresos, entre ellos la autosuperación por la vía del estudio y la frecuentación de la cultura. Aparece entonces un estudiante de medicina, aplicado y riguroso pero sin una vocación rutilante, que habiendo cursado dos materias se topa con los combates por la educación laica o libre y ahí se sumerge, como "atrapado por un torbellino". Es el encuentro con una escena, un tono, un tipo y una tradición: las discusiones definitivas de las asambleas universitarias y las batallas épicas de los estudiantes reformistas, ahora traicionados por uno de los suyos. Los comunistas, que habían dado su apoyo a Frondizi en las elecciones de febrero de 1958 y ahora se encontraban de nuevo ilegalizados, se encuentran entre los más feroces acusadores.

En esta escena se detecta la emergencia de un motivo que se tornará persistente: la voluntad

\footnotetext{
${ }^{3}$ Carlos Altamirano, Arturo Frondizi, o El hombre de ideas como político, Buenos Aires, FCE, 1998.
} 
temprana de forjarse una visión del mundo, una visión del mundo que debía ser provista por los libros pero que respondía a la incitación de la palabra en acción, de la polémica, de la discusión pública y de la conversación. Comienza el tránsito hacia la segunda estación, la del lector comunista, que dura también casi una década y que finaliza con un nuevo quiebre político y un nuevo desplazamiento: el golpe de 1966 y la llegada a Buenos Aires un año después.

Es posible pensar que en el comunismo los libros y los elementos que constituían su sistema, es decir, las revistas, los diarios, los panfletos, eran una curiosa posesión: se hacían cosas con los libros, básicamente se militaba una ciencia que permitía explicar casi todo, se estrechaba una pertenencia de iniciados, se formaba una comunidad investida de una misión que debía probarse en la disputa política e ideológica. Forjar una visión del mundo era, en efecto, algo más que leer los soporíferos manuales de marxismo. Si desde afuera la adquisición de aquel conjunto de saberes ideológicos que requería ser miembro de un "partido de vanguardia" podía parecer un catecismo, para los militantes comunistas significaba hacerse de una explicación del país y del mundo libre de prejuicios y supersticiones y, de paso, dominar un estilo, el de la polémica, a veces áspera y cargada de adjetivos. Dicho de otro modo: el militante comunista podía vivir con la certeza de poseer un sentido de la historia compartido por millones de personas a lo largo y ancho del planeta. Era, por esa razón, alguien que "sabía".

Esto era así para el tío Pedro y para el farmacéutico que orientó al pequeño puñado de jóvenes correntinos que en los primeros meses de 1961 decidieron unirse a la "tribu" del partido comunista local. Una elección medioambientalmente discordante, sin el lustre que podía tener en Buenos Aires, para la que se debía estar bien pertrechado en el saber militante, que era el motivo para sitiar a los libros. El asedio militante a los libros es un rasgo que no se olvida, una forma de leer distinta a las modalidades eruditas, académicas o recreativas. Permite forjarse una lectura política en el marco de una política de la lectura que se activa incluso cuando ya no existe un compromiso con ningún partido.

La lectura política es también un saber con otros y por eso Estaciones nos muestra una ecología de la lectura, la de las relaciones entre los lectores y los libros en espacios que no son el gabinete solitario sino el comedor universitario, los bares, las asambleas, la redacción de una revista, un cuarto de pensión, la calle. En esta ecología los libros producen una relación: la de la amistad y la camaradería aun con el adversario. Tarde o temprano, dice Carlos, uno termina encontrándose con los semejantes, a menudo a través de los libros.

Volvamos. A fines de la década de 1950 el comunismo era una fuerza poderosa en el clima cultural argentino, aunque acechada y en crisis. Las revelaciones de Nikita Jrushchov acerca de los crímenes del estalinismo y la oprobiosa invasión a Hungría a fines de 1956 trastocaron completamente la visión sobre la Unión Soviética y en todo el mundo comenzó a emerger una nueva izquierda. También en la Argentina, aunque en el particular clima de la revisión peronista. La Revolución Cubana, luego, desorganizó el tablero. Como un poderoso imán Cuba atrajo fuerzas que se venían desplegando desde tiempo atrás y las dotó de un nuevo sentido: la crisis del mundo comunista, la Guerra Fría, Bandung, la vía armada al socialismo, el Tercer Mundo se arremolinaron en torno a aquella revolución que además trastocó el acto de leer, al poner en entredicho el circuito tradicional entre doctrina y acción.

Por eso, en este itinerario la meditada conquista de los elementos mínimos de la cultura reformista coincidieron con un clima de época que empujaba hacia una biblioteca nueva, la de un marxismo que se liberaba de la tutela de las viejas formaciones comunistas y socialistas e ingresaba a la universidad bajo una forma filosófica que será pronto dominante: el existencialismo. Maurice Merleau-Ponty, a quien Héctor Agosti calificó como un profeta a la moda que más que filosofía hacía brebajes, cayó en las manos del joven estudiante que, en sus propias palabras, merodea, es decir, acecha, entre la curiosidad y las malas intenciones, unos títulos que en la jerga del partido son considerados hostiles y heréticos. Toda comunidad lectora, y el comunismo lo era, comparte criterios que dividen a los buenos y los malos libros y estrategias interpretativas que en este caso eran fuertemente custodiadas. En el comunismo se leía, pero no cualquier cosa ni de cualquier forma.

En 1961, luego del torbellino de la lucha estudiantil y de 10 meses como soldado conscripto en un pueblo que podemos imaginar 
un poco polvoriento, Carlos se hace

"oficialmente" comunista. Apenas unos meses después, Victorio Codovilla anuncia, con tonos pedagógicos y altisonantes, que el peronismo ha girado a la izquierda. Pronto el joven militante cae preso, asumiendo un paisaje de lectura casi ineludible para un comunista en las condiciones argentinas: la cárcel. Una experiencia que además remitía a una forma particular de martirologio: el de los militantes que soportan el encierro trastocando la temporalidad con un régimen dedicado a los libros. En ese año, durante dos meses, confinado por pintar consignas contra Frondizi, Carlos se vuelve un "agostiano", como dice refiriéndose a su admiración por quien fuera el intelectual más importante, al menos el menos ríspido y dogmático, del elenco comunista argentino: Héctor P. Agosti. En Estaciones, Agosti ocupa un capítulo entero. Es una estación que despega de la cronología, la única asociada a un nombre propio.

En el clima espeso de 1956, Agosti reunió en un libro que llevaba como título Para una política de la cultura varios artículos entre los que destacaba su intervención en la Primera Reunión de Intelectuales Comunistas. En el marco de un encuentro que era a todas luces un llamado al orden, Agosti decidió interpelar a sus camaradas, aún conmocionados por las revelaciones del xx Congreso del PCus, con una recomendación de lectura: vale la pena frecuentar los textos de Gramsci, les dijo, son uno de los modelos más eminentes de crítica marxista. El consejo resonó parcialmente y solo los más jóvenes estuvieron dispuestos a aceptar que el italiano era un héroe del antifascismo, sí, pero también un crítico del reduccionismo, el teleologismo y el desdén por los fenómenos de la ideología y la cultura que terminaron primando en el movimiento comunista internacional desde los años '30.

Agosti, refinado y barroco, culto y atento a lo que pasaba fuera de las fronteras de su fidelidad partidaria, poseía una sensibilidad de la que buena parte de sus camaradas carecía y sus libros acompañaron un movimiento que probablemente solo a él la pareciera urgente: en la Argentina posperonista también, como en el resto del mundo, el ciclo del estalinismo debía dar paso a otra cosa, si es que el comunismo quería sobrevivir. Aun con las limitaciones que pueden precisarse con la ventaja que ofrece la distancia, los temas de Agosti son los de una tradición de reflexión intelectual argentina que los sigue asediando, si bien con otros énfasis: la existencia de una literatura nacional y sus rasgos, la forja conflictiva de una tradición cultural común, las relaciones entre la cultura letrada y el mundo popular, los límites del liberalismo, la persistencia de una geografía cultural desigual, la inoperancia de las élites, la necesidad de una izquierda capaz de articular un lenguaje no puramente retórico, el lugar de los intelectuales en una sociedad fracturada y frente un pueblo que les es esquivo.

Lo cierto es que el "joven agostiano" sale de la cárcel decidido a dejar los libros de histología y a tomar el camino de las humanidades, de la filosofía primero, de las letras finalmente, con la convicción de que la universidad le ayudará a forjarse un marxismo menos pobre del que asume que tiene. La decisión es cultivarse para militar. Cinco años después, casi en coincidencia con la llamada Revolución Argentina, Carlos obtendrá su único título universitario: licenciado en letras. Sin embargo, cosa curiosa o no tanto, no será esta adscripción disciplinar con la que se lo asocia habitualmente: los títulos de sociólogo, politólogo, historiador y ensayista político aparecen con frecuencia asociados a su nombre.

Con el recién estrenado título, encuentra trabajo como profesor en un pueblo rural del Chaco, pero dura poco. Enseguida alguien descubre su afiliación política y lo despiden, en un clima de hostilidad anticomunista que fue una constante en la cultura política argentina del siglo xx. Este tropiezo lo empuja a tomar la decisión de mudarse a Buenos Aires, a los 28 años. En la ciudad capital la comunidad de los libros previsiblemente se amplía. De este tramo queda el recuerdo del encuentro con la obra de Louis Althusser, cuya lectura entrena en los cursos de un excomulgado del partido, Raúl Sciarreta, quien junto a José María Aricó había acompañado a Agosti en la empresa de traducción de la obra de Gramsci, la primera realizada fuera de Italia. A mediados de 1960 el comunismo se fractura de un modo que no tendrá retorno y Carlos sigue una de las sendas de aquella escisión, el maoísmo. Es la época del paso por el trabajo editorial, del boom latinoamericano y de la revista Los Libros. Una década memorialísticamente breve, volcada hacia la configuración de un saber militante que en esta estación deja conservar pocos recuerdos de lectura. 
En 1977, Estaciones recupera un nuevo episodio que pone a la vista la persistencia, aun en condiciones extremas y ya por fuera de una estructura partidaria, de la lectura militante: un reflejo, dice Carlos, que lo lleva a leer El Capital de Carlos Marx, en la traducción de Pedro Scaron, y a fundar un pequeño grupo que luego se convertirá en una de las revistas más importantes y longevas de la cultura argentina del siglo xx: Punto de Vista. Se inicia entonces otra estación cuya temporalidad está marcada por el terror de la dictadura, la guerra y el retorno a la democracia a través de un proyecto político que fue también un ciclo de ilusión y desencanto. En esta estación y las siguientes el militante dejará paso al profesor universitario, al investigador, al analista político y al intelectual, a alguien que, finalmente, lee la política con mediaciones, como parte de una profesión. En esta etapa, el peronismo, aquel que había llegado junto con el primer libro en el verano tórrido de 1946, es asediado con una nueva grilla, la del lector erudito que sin embargo asume que su objeto es también, o necesariamente, una interrogación sobre la cultura en la que se ha formado, las izquierdas.

Unas izquierdas que en su largo periplo por la Argentina del siglo Xx no pudieron afrontar la tarea de desarrollar una fuerza socialista con base popular, pero que aportaron a la creación de una comunidad de ideas, de prácticas y de relaciones forjadas por muchas formas de camaradería, entre ellas, la camaradería de los libros. De ese mundo comunista que ya no existe, tal vez sea esta, la comunidad de la política y los libros, la más sentida forma de su persistencia. 